University of Nebraska - Lincoln

DigitalCommons@University of Nebraska - Lincoln

Faculty Publications: Department of

Entomology

Entomology, Department of

2-11-2019

Southern Corn Rootworm (Coleoptera: Chrysomelidae) Adult

Emergence and Population Growth Assessment After Selection

With Vacuolar ATPase-A double-stranded RNA Over Multiple

Generations

\author{
Adriano E. Pereira \\ University of Nebraska - Lincoln, aelias374@yahoo.com.br \\ Brigitte Tenhumberg \\ University of Nebraska-Lincoln, btenhumberg2@unl.edu \\ Lance J. Meinke \\ University of Nebraska - Lincoln \\ Blair D. Siegfried \\ University of Florida
}

Follow this and additional works at: https://digitalcommons.unl.edu/entomologyfacpub

Part of the Entomology Commons

Pereira, Adriano E.; Tenhumberg, Brigitte; Meinke, Lance J.; and Siegfried, Blair D., "Southern Corn Rootworm (Coleoptera: Chrysomelidae) Adult Emergence and Population Growth Assessment After Selection With Vacuolar ATPase-A double-stranded RNA Over Multiple Generations" (2019). Faculty Publications: Department of Entomology. 780.

https://digitalcommons.unl.edu/entomologyfacpub/780

This Article is brought to you for free and open access by the Entomology, Department of at DigitalCommons@University of Nebraska - Lincoln. It has been accepted for inclusion in Faculty Publications: Department of Entomology by an authorized administrator of DigitalCommons@University of Nebraska - Lincoln. 


\title{
Southern Corn Rootworm (Coleoptera: Chrysomelidae) Adult Emergence and Population Growth Assessment After Selection With Vacuolar ATPase-A double-stranded RNA Over Multiple Generations
}

\author{
Adriano E. Pereira, ${ }^{1,5, \bullet}$ Brigitte Tenhumberg, ${ }^{2}$ Lance J. Meinke, ${ }^{3}$ and Blair D. Siegfried ${ }^{4}$
}

'Plant Genetics Research Unit, USDA/ARS, University of Missouri, 205 Curtis Hall, Columbia, M0 65211, ${ }^{2}$ School of Biological Sciences and Department of Mathematics, University of Nebraska, Lincoln, NE 68588, ${ }^{3}$ Department of Entomology, University of Nebraska, Lincoln, NE 68583, ${ }^{4}$ Department of Entomology and Nematology, University of Florida, Gainesville, FL 32611, and ${ }^{5}$ Corresponding author, e-mail: aelias374@yahoo.com.br

Subject Editor: Aaron Gassmann

Received 19 May 2018; Editorial decision 13 December 2018

\begin{abstract}
The southern corn rootworm, Diabrotica undecimpunctata howardi Barber (Coleoptera: Chrysomelidae), was exposed over multiple generations to vacuolar (v)ATPase-A double-stranded (ds)RNA, first as adults and later, as neonate larvae. During adult selection, high mortality and lower fecundity were observed in the RNAi-selected cages after beetles were exposed to sublethal dsRNA concentrations that varied between $\mathrm{LC}_{40}$ and $\mathrm{LC}_{75}$. During larval selection, a delay in adult emergence and effects on population growth parameters were observed after neonates were exposed to sublethal dsRNA concentrations that varied between $\mathrm{LC}_{50}$ and $\mathrm{LC}_{70}$. Some of the parameters measured for adult emergence such as time to reach maximum linear adult emergence, time elapsed before attaining linear emergence, termination point of the linear emergence, and total days of linear emergence increase, were significantly different between RNAi-selected and control colonies for at least one generation. Significant differences were also observed in population growth parameters such as growth rate, net reproductive rate, doubling time, and generation time. After seven generations of selection, there was no indication that resistance evolved. The sublethal effects caused by exposures of southern corn rootworm to dsRNAs can affect important life history traits and fitness especially through delays in adult emergence and reduction in population growth. Although changes in susceptibility did not occur, the observation of sublethal effects suggests important responses to potential selection pressure. Assuming resistance involves a recessive trait, random mating between susceptible and resistant individuals is an important factor that allows sustainable use of transgenic plants, and delays in adult emergence observed in our studies could potentially compromise this assumption.
\end{abstract}

Key words: RNA interference, Diabrotica, Diabrotica undecimpunctata howardi, insect resistance management, corn rootworm

RNA interference (RNAi) is a gene silencing technique that uses double-stranded (ds)RNA to suppress gene expression (Fire et al. 1998, Fire 2007). This unique mode of action and lethality associated with knockdown of essential genes makes RNAi an important option as a novel pest control technique (Huvenne and Smagghe 2010, Gu and Knipple 2013). RNAi has been shown to be effective against both the western corn rootworm, Diabrotica virgifera virgifera LeConte and the southern corn rootworm, Diabrotica undecimpunctata howardi Barber in larvae (Baum et al. 2007; Bolognesi et al. 2012; Bachman et al. 2013; Koci et al. 2014; Levine et al. 2015; Pereira et al. 2016, 2017a) and adults (Rangasamy and Siegfried
2012; Khajuria et al. 2015; Vélez et al. 2016; Fishilevich et al. 2016; Pereira et al. 2016, 2017a). Registration of transgenic maize plants that express RNAi traits for commercial sale has recently been approved (EPA 2017) and will be commercialized as soon as key markets approve (Ahmad et al. 2016, Bachman et al. 2016). RNAi for rootworm control will be a new mode of action that can be pyramided with toxins from Bacillus thuringiensis (Bt) and assist in resistance management for transgenic plants developed for rootworm control (Head et al. 2017).

The corn rootworm complex includes the southern corn rootworm, western corn rootworm, and northern corn rootworm, 
Diabrotica barberi Smith \& Lawrence. Southern corn rootworm occurs in the southeastern region of the United States and migrates during the spring and summer to most of the U.S. east of the Rocky Mountains (Krysan 1986). The southern corn rootworm is considered a generalist plant pest that feeds on a wide variety of plants, including many grasses, cucurbits, soybeans, and peanuts, with corn as a major host (Arant 1929, Isely 1929, Meinke et al. 1985). Adults feed on pollen, foliage, and flowers of many plants, causing damage to ornamental plants, and to vegetable crops such as cucurbits, tomatoes, and dry beans (Arant 1929, Isely 1929). Southern corn rootworm larvae are root feeders and cause a similar type of injury to corn as the related western corn rootworm. Western corn rootworm larval feeding can cause root pruning, a reduction in water and nutrient uptake, plant lodging, and grain yield loss (Riedell 1990, Tinsley et al. 2013).

Western corn rootworms have shown to be highly adaptable to selection pressure (Miller et al. 2009). Resistance evolution to control tactics started in late 1950s to insecticides when western corn rootworm evolved resistance to cyclodienes (Ball and Weekman 1962, Wang et al. 2013) and later to carbamates, methyl parathion (Meinke et al. 1998, Zhu et al. 2001), and recently to pyrethroids (Pereira et al. 2015, 2017b). The western corn rootworm has also evolved a behavioral resistance to crop rotation in the eastern Corn Belt (Levine et al. 2002) and recently to Bt corn (Gassmann et al. 2011, 2016; Wangila et al. 2015; Ludwick et al. 2017). Cases of western corn rootworm resistance evolution in as few as three generations of larval exposure to $\mathrm{Bt}$ expressing corn plants have been reported in the laboratory (Meihls et al. 2008, 2011, 2012, 2016; Frank et al. 2013).

Resistance evolution in western corn rootworm to RNAi has been established in the laboratory from adults emerged from corn plants expressing dsRNA in a field experiment (Khajuria et al. 2018). RNAi resistance has been observed in the nematode, Caenorhabditis elegans, where researchers exposed lab populations to chemical mutagens and reported reduced gene silencing to several dsRNAs targeting germline-specific genes involved in embryonic development and somatically expressed genes targeting a cuticle collagen gene (Tabara et al. 1999). In addition, a wild C. elegans population found in Hawaii exhibited a mutation in the Argonaute gene which is involved in the RNAi pathway, thus affecting RNAi function (Pollard and Rockman 2013).

Although southern corn rootworm differs from western corn rootworm in a number of life history parameters and management practices, southern corn rootworm was chosen as a model
Diabrotica species to investigate potential responses to selection by repeated exposure to a lethal RNAi target sequence over multiple generations because it is easier to rear in the lab and because there were rearing diets available for both larvae and adults. In addition, the southern corn rootworm does not have an obligatory diapause and field collections can be reared directly without establishing a non-diapause strain. The objectives of this research were 1) to select an southern corn rootworm field-collected laboratory colony for resistance to dsRNA targeting the vacuolar (v)ATPase-A gene which encodes an important proton pump and $\mathrm{pH}$ regulator located in the cell membrane; 2) calculate and compare population growth parameters such as intrinsic rate of increase $(r)$, net reproductive rate $\left(R_{0}\right)$, generation time $(T)$, doubling time $(D T)$, and finite rate of increase or growth rate in discrete time $(\lambda)$, between RNAi-exposed individuals and control, and 3) assess adult emergence after exposure of southern corn rootworm neonates to different $v$ ATPase-A dsRNA concentrations during selection for resistance.

\section{Materials and Methods}

\section{Southern Corn Rootworm Field Population}

Approximately 12,000 southern corn rootworm adult males and females were collected from commercial pumpkin fields and wild sunflower in Lancaster County, Nebraska, to establish a laboratory colony. Beetles were maintained in $30 \mathrm{~cm}^{3}$ BugDorm cages (MegaView Science Co., Ltd., Taichung, Taiwan) provided with dry adult artificial diet (Frontier Agricultural Sciences, Newark, DE) and water in a $250-\mathrm{ml}$ plastic bottle containing a 15 -cm-long cotton wick (Richmond Dental \& Medical, Charlotte, SC) suspended through a hole in the lid. Diet and cotton wicks were changed twice a week. Before selection began, on generation 1 (G1), beetles were split into two colonies. The control colony was never exposed to dsRNA and the other colony was exposed to different concentrations $\left(\mathrm{LC}_{50} \mathrm{cal}-\right.$ culation described below in $\mathrm{LC}_{50}$ dsRNA calculation) of dsRNA (Table 1), based on the number of insects surviving, as adult first and afterward as neonates (Fig. 1).

\section{Southern Corn Rootworm Lab Rearing}

Rearing methods were similar to those described by Jackson (1986). Eggs were collected weekly in $9.0 \mathrm{~cm}$ diameter $\times 1.4 \mathrm{~cm}$ height Petri dishes (Fisher Scientific, Pittsburgh, PA) containing layers of $6.0 \times 12.8 \mathrm{~cm} \sim 50 \% \mathrm{w} / \mathrm{w}$ moistened gauze as oviposition substrate

Table 1. Summary of selection for resistance in southern corn rootworm adults exposed to $v A T P a s e-A$ dsRNA concentrations (ng/cm ${ }^{2}$ ) overlaid on artificial diet and percentage of survivorship $( \pm \mathrm{SE})$ measured $10 \mathrm{~d}$ after the last day of exposure to dsRNA

\begin{tabular}{|c|c|c|c|c|c|c|}
\hline \multirow[b]{2}{*}{ Generation $^{a}$} & \multirow[b]{2}{*}{ Number of 3-4 d exposure periods to dsRNA } & \multirow[b]{2}{*}{ dsRNA concentration $\left(\mathrm{ng} / \mathrm{cm}^{2}\right)$} & \multicolumn{4}{|c|}{$\begin{array}{l}\% \text { adult survival }( \pm \mathrm{SE}) 10 \mathrm{~d} \text { after last } \\
\text { day of exposure to dsRNA in cages }\end{array}$} \\
\hline & & & $N^{b}$ & RNAi-selected ${ }^{d}$ & $N^{b}$ & Control $^{e}$ \\
\hline 2 & 3 & 244.3 & 1 & $18^{c}$ & 3 & $75 \pm 2.6$ \\
\hline 4 & 1 & 97.6 & 2 & $11 \pm 10.1$ & 2 & $71 \pm 1.7$ \\
\hline \multirow[t]{2}{*}{5} & 2 & 16.4 & 3 & $20 \pm 5.4$ & 4 & $54 \pm 5.2$ \\
\hline & 1 & 55.4 & & & & \\
\hline 6 & 2 & 65 & 4 & $5 \pm 2.4$ & 4 & $75 \pm 2.1$ \\
\hline
\end{tabular}

${ }^{a}$ Insects from G3 and G7 were not exposed.

${ }^{b}$ Number of rearing cages.

No standard error reported because of insufficient number of replicates.

${ }^{d}$ RNAi-selected strain: beetles were exposed to dsRNA on agar-based artificial diet and switched to dry artificial diet (Frontier Agricultural Sciences, Newark, $\mathrm{DE})$.

${ }^{e}$ Control strain: beetles fed on agar-based artificial diet for the same period as RNAi-selected beetles were exposed to dsRNA before switched to dry artificial diet. 


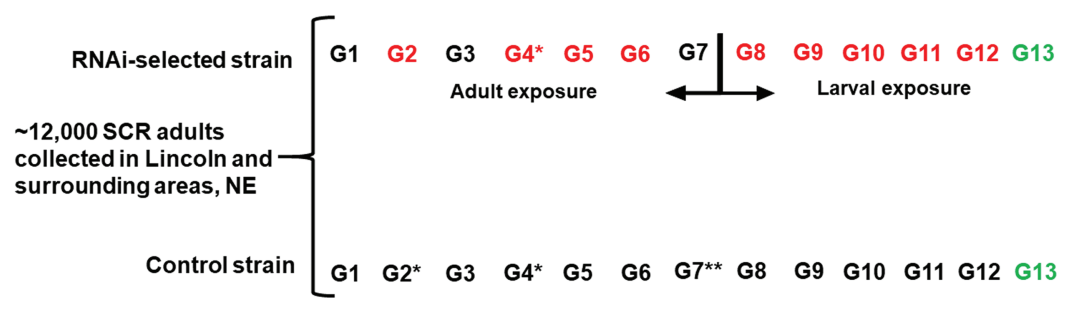

Fig. 1. Schematic illustration of selection for resistance to $v A T P a s e-A$ dsRNA in southern corn rootworm. Over 12,000 adult beetles were collected in Lincoln and surrounding areas, Nebraska. The beetles were split in two colonies, one that was exposed to vATPase-A dsRNA in generations 2, 4-6 as adults and generations 8-12 as larvae. On generation 13, adult beetles from both colonies were exposed to LC $_{90} v A T P a s e-A$ dsRNA on artificial diet and the colonies were terminated afterward. *Adult LC50 assay; ** Larval LC50 assay.

$(12.8 \mathrm{~cm} \times 550.0 \mathrm{~cm}$, Surgitube, Derma Sciences Inc., Princeton, NJ). Eggs were washed from the gauze and collected using a \# 30-mesh sieve $(500 \mu \mathrm{m})$ on top of a \# 60-mesh sieve $(250 \mu \mathrm{m})($ Hogentogler $\&$ Co. Inc., Columbia, MD) in tap water at room temperature. The eggs were placed in clean $9.0 \mathrm{~cm}$ Petri dishes containing fine autoclaved soil sifted through \# 60-mesh sieve and stored at $14^{\circ} \mathrm{C}$ until use. Eggs were then placed at room temperature of $25^{\circ} \mathrm{C}$ to hatch. Two different rearing containers were used depending on the number of eggs and neonates hatched. Between 150 and 180 neonates were transferred to $34.6 \times 21.0 \times 12.4 \mathrm{~cm}$ or $350-400$ neonates were transferred to $58.4 \times 41.3 \times 15.2 \mathrm{~cm}$ clear plastic containers (Sterilite Corporation, Clinton, SC) planted with a stand of about 1-2 seeds $/ \mathrm{cm}^{2}$ of untreated, non-transgenic corn (Reid's yellow dent, Seed Savers Exchange, Decorah, IA) in a potting soil mix (Schultz Moisture Plus, Oldcastle Lawn \& Garden, Inc., Atlanta, GA). Containers with corn plants were maintained in a walk-in chamber at $25 \pm 1^{\circ} \mathrm{C}$, relative humidity of $60-80 \%$ and photoperiod of $16: 8$ (L:D) h. After emergence, adults were transferred and maintained in BugDorm cages provided with dry southern corn rootworm artificial diet (Frontier Agricultural Sciences) and water.

The percentage egg hatch was determined during generations (G) G3, G5, and G9 by placing egg samples of 100-150 eggs on moistened filter paper in $5.0 \mathrm{~cm}$ diameter Petri dishes (\#7242, Pall Corporation, Port Washington, NY) with 6 Petri dishes/colony. Egg hatch was recorded daily until no hatch was observed for three consecutive days.

\section{LC50 dsRNA Calculation}

The lethal concentration that kills $50 \%$ of insects tested $\left(\mathrm{LC}_{50} \mathrm{~s}\right)$ was calculated on G2 (control) and G4 (control and RNAi-selected) for adults, and G7 (control) for neonates (Fig. 1). The adult and larval $\mathrm{LC}_{50}$ values for $v$ ATPase- $A$ dsRNA were determined by exposing the insects to increasing concentrations of dsRNA $(0.1$, $1.0,10,100,1000 \mathrm{ng} / \mathrm{cm}^{2}$ ) plus control (nuclease-free water only). For adults, 12 artificial diet pellets cut with a cork borer $(4.0 \mathrm{~mm}$ diameter $\times 2.0 \mathrm{~mm}$ height; area $\left.=0.1256 \mathrm{~cm}^{2}\right)$ were placed in each well $(5.0 \mathrm{~cm} \times 2.5 \mathrm{~cm} \times 2.5 \mathrm{~cm})$ with 10 unsexed adults per well in 16-well trays (C-D International, Pitman, NJ) using four wells per treatment. Each pellet was treated with $3 \mu$ of dsRNA solution/ pellet for each respective concentration. Trays with freshly treated diet were provided every other day for $10 \mathrm{~d}$ after which beetles were provided with untreated diet. Mortality was recorded after 15 d. Control wells were treated with nuclease free water only. Larval susceptibility was determined using 96-well plates (Costar \# 3595, Corning Incorporated, Corning, NY) filled with $200 \mu \mathrm{l}$ of artificial diet (Frontier Agricultural Sciences, Newark, DE) and treated with increasing concentrations of $v$ ATPase- $A$ dsRNA $(0.01,0.1,1.0,10$, $100,1,000 \mathrm{ng} / \mathrm{cm}^{2}$ ) plus control (nuclease free water only). Eggs were surface sterilized as described in Pleau et al. (2002), placed in 9-cm Petri dish with moist filter paper and held in an incubator at $27^{\circ} \mathrm{C}, 80 \% \mathrm{RH}$ until hatching. Diet was surface treated with $20 \mu \mathrm{l}$ of dsRNA solution for each respective concentration, allowed to dry and a single neonate was transferred to the wells using a fine camel hair brush. Three plates were used for each bioassay with 12 neonates per row for a total of 36 neonates for each concentration. Each plate was sealed with plate sealer (Excel Scientific, Inc., Victorville, CA; \# TSS-RTQ-100) with one hole punched per well using a \# 0 insect pin and held at $25^{\circ} \mathrm{C}, 80 \% \mathrm{RH}$ in the dark. Mortality was recorded after $12 \mathrm{~d}$. Control wells were treated with $20 \mu \mathrm{l}$ of nuclease free water. Only those bioassays in which control mortality was $<20 \%$ and that did not exhibit microbial contamination of diet, were included in further analysis.

\section{Selection for Resistance to vATPase-A dsRNA}

For the RNAi-selected colony, adults from G2 and G4-G6 were exposed to dsRNA by feeding on agar-based corn rootworm adult diet modified from Branson and Jackson (1988) and described in Khajuria et al. (2015) in $9.0 \mathrm{~cm}$ Petri dishes filled with approximately 3-4 mm with artificial diet. The diet was surface treated with $900 \mu \mathrm{l}$ of dsRNA solution that covered the surface evenly, let dry and adults fed continuously on the treated diet for 3-4 d. Each cage was provided with one treated diet plate per approximately 100-150 adults. After exposure to dsRNA treated diet, adults were provided with untreated dry artificial diet and water. During adult selection, adults from the control colony were maintained on untreated artificial diet for the same period as the selected colony fed on dsRNA and then switched over to dry artificial diet. Adult mortality and egg production were recorded weekly in each cage and during each generation.

After four generations on adults, selection was shifted to larvae in order to increase the number of individuals exposed to dsRNA at each generation. For larval selection (G8-G10), neonates from the RNAi-selected adults (G7) were exposed to dsRNA on treated artificial diet in $15.0 \mathrm{~cm} \times 1.5 \mathrm{~cm}$ Petri dishes (VWR International, Radnor, PA) overlaid with dsRNA solution ( 1.5 ml and let dry) and allowed to feed for $4 \mathrm{~d}$ (Table 2). After exposure to dsRNA treated artificial diet, larvae were transferred to rearing containers with germinated seed corn and reared to adults as described above in the rearing section. Neonates from the control colony were maintained on untreated larval artificial diet for the same period as the selected neonates before transferred to containers with germinated seed corn.

To assure enough insects to continue the generations, the concentration of dsRNA used during the selection were adjusted based on the number of surviving adults. If the number of eggs laid by surviving adults after dsRNA exposure during adult selection, or number of adults emerging from containers after larval exposure to 
Table 2. Summary of selection for resistance in southern corn rootworm neonates exposed to vATPase- $A$ dsRNA concentrations (ng/cm ${ }^{2}$ ) overlaid on artificial diet and percentage survivorship $( \pm$ SE) to adult stage from containers per generation after dsRNA exposure

\begin{tabular}{|c|c|c|c|c|c|c|}
\hline \multirow[b]{2}{*}{ Generation } & \multirow[b]{2}{*}{ Number of 4-d exposure periods to dsRNA } & \multirow[b]{2}{*}{ dsRNA concentration $\left(\mathrm{ng} / \mathrm{cm}^{2}\right)$} & \multicolumn{4}{|c|}{$\begin{array}{l}\% \text { adult emergence }( \pm \mathrm{SE}) \text { from rearing } \\
\text { containers }\end{array}$} \\
\hline & & & $N^{\mathrm{a}}$ & RNAi-selected ${ }^{b}$ & $\mathrm{~N}^{a}$ & Control $^{c}$ \\
\hline 8 & 1 & 10 & 13 & $5.2 \pm 2.2$ & 26 & $23.5 \pm 4.0$ \\
\hline 9 & 2 & 15 & 2 & $7.0 \pm 3.2$ & 6 & $61.1 \pm 7.7$ \\
\hline 10 & 1 & 15 & 10 & $18.2 \pm 1.7$ & 4 & $13.2 \pm 2.5$ \\
\hline
\end{tabular}

${ }^{a}$ Number of rearing containers.

${ }^{b}$ RNAi-selected strain: Neonate larvae were exposed to dsRNA on artificial diet (Frontier Agricultural Sciences, Newark, DE) and transferred to rearing containers containing germinating untreated corn seeds.

${ }^{c}$ Control strain: neonate larvae fed on southern corn rootworm artificial diet for the same period as RNAi-selected neonates were exposed to dsRNA before transferred to rearing containers with germinating corn.

Table 3. Cumulative number of eggs $( \pm \mathrm{SE})$ per 10 adults from rearing cages during selection for resistance to $v A T P a s e-A$ dsRNA in southern corn rootworm

\begin{tabular}{|c|c|c|c|c|}
\hline Life stage exposed & Generation & Colony & Cumulative number (mean \pm SE) of eggs per 10 adults & \# Cages \\
\hline \multirow[t]{2}{*}{ Adult } & 2 & Control & $755.7 \pm 20.3$ & 3 \\
\hline & & RNAi & $83.3^{a}$ & 1 \\
\hline \multirow[t]{2}{*}{ Adult } & 4 & Control & $1991.8 \pm 45.9^{b}$ & 2 \\
\hline & & RNAi & $798.7 \pm 33.4$ & 2 \\
\hline \multirow[t]{2}{*}{ Adult } & 5 & Control & $2183.6 \pm 236.1^{b}$ & 4 \\
\hline & & RNAi & $1176.8 \pm 178.1$ & 3 \\
\hline \multirow[t]{2}{*}{ Adult } & 6 & Control & $1221.7 \pm 91.6^{b}$ & 4 \\
\hline & & RNAi & $418.9 \pm 68.8$ & 4 \\
\hline \multirow[t]{2}{*}{ Larval } & 8 & Control & $1764.5 \pm 472.6$ & 3 \\
\hline & & RNAi & $1150.1^{a}$ & 1 \\
\hline \multirow[t]{2}{*}{ Larval } & 9 & Control & $3873.9 \pm 176.1$ & 4 \\
\hline & & RNAi & $2821.7^{a}$ & 1 \\
\hline \multirow[t]{2}{*}{ Larval } & 10 & Control & $2467.3^{a}$ & 1 \\
\hline & & RNAi & $2265.1 \pm 318.9$ & 2 \\
\hline
\end{tabular}

${ }^{a}$ No standard error reported because of insufficient number of replicates.

${ }^{b}$ Significantly different with pair-wise comparisons between control and RNAi-selected strains using PROC GLIMMIX in SAS, at $\alpha<0.05$. Analysis was performed only on those generations that each colony had more than one cage.

dsRNA was high enough, a higher concentration was used; otherwise, a lower concentration was used. Concentrations can be seen in Tables 1 (adult selection) and 2 (larval selection).

During all generations of adult selection for resistance, adult mortality in the RNAi-selected cages was compared with the control cages $10 \mathrm{~d}$ after the last day of dsRNA exposure. The cumulative number of eggs per 10 individuals in the cages was recorded until oviposition of the RNAi-selected colony was no longer observed. The egg production was estimated per 10 adults rather than per female to minimize the labor associated with sexing individual beetles under the microscope; besides, the proportion of males and females in the cages changed over time, with more males at the beginning of the generation and more females towards the end of the generation. Between one and four cages were maintained per colony for each generation (Table 3) with each cage containing between 140 and 1,000 beetles for the RNAi-selected colony, and between 500 and 1,200 beetles for the unselected colony. To ensure enough individuals were available to maintain the colony, selection for resistance was not performed in G3 and G7 because of the low number of eggs generated by the adult survivors after exposure to dsRNA (Fig. 1).

\section{Southern Corn Rootworm-Specific vATPase-A dsRNA Synthesis}

For adult selection, dsRNA was synthesized in the Toxicology lab, Department of Entomology. For larval selection, a large amount
$(10 \mathrm{mg})$ of lyophilized $v$ ATPase- $A$ dsRNA was purchased from Genolution Inc. (Seoul, South Korea). A single southern corn rootworm adult was homogenized in a $1.5 \mathrm{ml}$ microcentrifuge tube to extract total RNA using TRIzol (Invitrogen, Carlsbad, CA) after which $1.0 \mu \mathrm{g}$ of total RNA was used to synthesize cDNA using QuantiTect reverse transcription kit (Qiagen, Valencia, CA). The PCR templates for in vitro transcription of southern corn rootworm-specific dsRNAs were amplified using gene-specific primers from western corn rootworm tailed with the T7 polymerase promoter sequence (TAATACGACTCACTATAGGG). The primers for the putative western corn rootworm $v$ ATPase subunit- $A$ amplified a $258 \mathrm{bp}$ fragment derived from an expressed sequence tag (accession \# CN498337.): 5'-(T7)TATTGTACAGGTG-3' and 5'(T7)CAATTTCCAAG-3'. After confirming template sequence for southern corn rootworm from western corn rootworm, southern corn rootworm-specific $v$ ATPase-A dsRNA was synthesized in vitro using MEGAscript high-yield transcription kit (Applied Biosystems Inc., Foster City, CA), purified using a RNAeasy Mini kit (Qiagen) following the manufacturer's protocol and stored at $-20^{\circ} \mathrm{C}$ (Rangasamy and Siegfried 2012). The southern corn rootworm $v$ ATPase-A dsRNA primers amplified a 289 bp fragment. Gene knockdown in southern corn rootworm larvae and adults by $v$ ATPase- $A$ dsRNA has been previously confirmed by quantitative real-time PCR and is described and reported in Pereira et al. (2016). 


\section{Diagnostic Bioassay}

During the 13th generation of rearing and selection, the number of adults and eggs were insufficient to perform a complete concentrationresponse bioassay. Therefore, adult susceptibility was assessed by exposure to a single concentration of $210 \mathrm{ng} / \mathrm{cm}^{2}$ of $v$ ATPase-A dsRNA, which approximated the $\mathrm{LC}_{90}$ calculated for the control colony at G4. Mortality was recorded after $10 \mathrm{~d}$ for both RNAi-selected and control colonies using the methods described previously for bioassays. Diagnostic bioassays were replicated in 15 -well trays with each well containing 10 beetles feeding on dsRNA treated artificial diet. Bioassays were performed twice which yielded 30 replicates per treatment.

\section{Life Table Analysis}

Intrinsic rate of increase or growth rate $\left(r_{m}\right)$ (Gotelli 1995) was calculated for RNAi-selected and control colonies during the larval selection for resistance in G9 and G10 based on weekly mortality and fecundity data obtained from each rearing cage and number of beetles emerging from rearing containers (adult emergence from containers was not recorded during G8). Fecundity was calculated per 10 adults in each cage. Mortality and fecundity data in the cages were averaged over one to four cages per colony (Table 3 ). The number of rearing containers for both dsRNA-exposed and control varied between 2 and 15 for each colony and at each generation (Table 2).

We estimated the population growth potential for RNAi-selected and control colonies using the Euler equation (Gotelli 1995).

$$
1=\int_{0}^{k} \exp \left(-r_{m} x\right) l(x) b(x),
$$

where $r_{m}$ is the intrinsic growth rate or growth rate in continuous time, $l(x)$ is the survivorship of an individual of age $x, b(x)$ is the average number of female offspring born per unit time to an individual of age $x$, and $k$ indicates the maximum age of a cohort. This model ignores density dependent processes and assumes the population is growing exponentially. The equation was solved using the uniroot-function in the software package $\mathrm{R}$ (R-Core-Team 2017). We also calculated the growth rate in discrete time $\left(\lambda=\exp \left(r_{m}\right)\right)$, the net reproductive rate $\left(R_{0}=\sum_{x=0}^{k} l(x) b(x)\right)$, the generation time $\left(T=\frac{\sum_{x=0}^{k} l(x) b(x) x}{l(x) b(x)}\right)$, and the doubling time DT $\left(D T=\log (2) / r_{m}\right)$.

The values estimated for DT are medians instead of means because

some of the values for $r_{m}$ in the replicates were close to zero and thus, would generate higher and inaccurate values for $D T$.

\section{Adult Emergence}

Adult emergence was recorded from rearing containers for G9 and G10 during larval selection for resistance. During this period, neonates were exposed to varied concentrations of $v$ ATPase- $A$ dsRNA treated artificial diet for $4 \mathrm{~d}$ (Table 2) before being transferred to larval rearing containers. Adult emergence was recorded daily from each container for approximately $2 \mathrm{wk}$ until no beetles emerged for four consecutive days.

\section{Statistical Analysis}

POLOPlus-PC software (LeOra 1987) probit analysis was used to analyze the mortality and generate the $\mathrm{LC}_{50} \mathrm{~s}$. POLOPlus corrects for control mortality automatically using Abbott's formula (Abbott 1925). Egg viability (egg hatch) from each strain (control and RNAiselected) during G3, G5, and G9 and mean egg production per 10 adults in the cages were set up in a randomized complete block design and were analyzed by pair-wise comparisons in least square means using PROC GLIMMIX in SAS 9.4, at $\alpha<0.05$. For viability, eggs were collected in three different dates (block), one cohort per week, the replicates were the random effects and the egg hatch data were the fixed effects. For egg production per 10 adults, replicates were the random effects and eggs/10 adults were the fixed effects.

For the statistical analysis of the life-table parameters we used R (version 3.4.3, R Core Team 2017). Analysis of variance was performed using treatment and generation as independent variables and the life table parameters as dependent variables. We also tested for an interaction between treatment and generation. We tested the normality assumptions with QQ-plots and presented normal distribution. Then we calculated the least square means and performed an ad hoc Tukey test.

A completely randomized design with an unbalanced number of replicates (containers) was used to compare cumulative adult emergence in G9 and G10. The replicates were random effects and strains (control and selected-RNA) were fixed effects. Data were fitted to a nonlinear regression model (Fig. 2) using the Gauss-Newton iterative method (Stilwell et al. 2010). Each generation was analyzed separately, therefore, data are independent. The parameters (in days) such as 1) time elapsed before reaching linear emergence $\left[E_{\text {onset }}=\right.$ $(b-2) /-c], 2)$ inflection point or time to reach maximum linear emergence $\left.\left(E_{\max }=b /-c\right), 3\right)$ termination point of the linear emergence $\left[E_{\text {end }}=(b+c) /-c\right]$, and 4) total days of linear emergence increase $\left(E_{\text {duration }}=4 /-c\right)$, where ' $b$ ' and 'c' are constants generated in PROC NLIN in SAS 9.4 (Boetel et al. 2003), were calculated for both colonies (Dybing et al. 1988, Boetel et al. 2003). The data generated for the parameters were checked for normality and presented normal distribution. Parameters were pair-wise compared between the colonies in least square means using PROC GLIMMIX in SAS 9.4 (SAS Institute, Cary, NC), at $\alpha<0.05$.

\section{Results}

\section{Selection for Resistance}

After seven generations of selection (four in adults; three in larvae), there was no detectable change in susceptibility of southern corn rootworm to vATPase- $A$ dsRNA. Adult survivorship, when compared with the control colony $10 \mathrm{~d}$ after the last day of exposure to

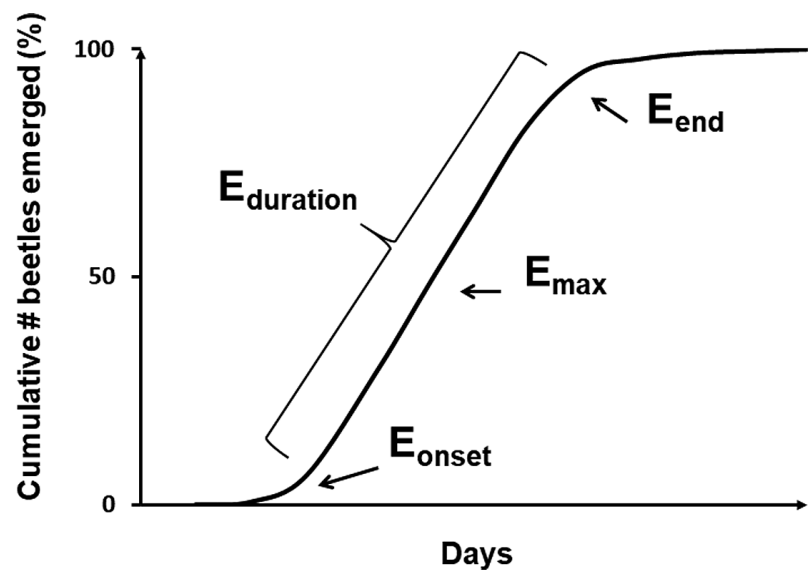

Fig. 2. General curve of cumulative number of southern corn rootworm beetles emerged from containers and the respective parameters measured: Eonset, time elapsed before reaching linear emergence; Emax, time to reach maximum linear emergence; Eend, termination point of the linear emergence; Eduration, duration of linear emergence increase (see Materials and Methods for more details). 
dsRNA varied from 5 to $30 \%$ in the RNAi-selected colony and from 54 to $75 \%$ in the control colony (Table 1). Total percentage survival from larva to adult in each rearing container from G8 to G10 is presented in Table 2. Survival in the RNAi-selected and control colonies varied from 5 to $18 \%$ and 13 to $61 \%$, respectively.

At G4, G5, and G6, the cumulative number of eggs per 10 adults was significantly higher in control cages when compared to RNAiselected cages (Table 3). During G2 and larval selection generations, there were not enough beetles generated to provide adequate replication; therefore, statistical comparisons were not possible (Table 3 ). However, egg production was consistently higher in the control colony when compared to the RNAi-selected colony.

Mean percentage egg hatch was not significantly different between RNAi- selected and control colonies during G3 (control $=58 \pm 2 \%$; RNAi-selected $=59 \pm 8 \%$ ) and G9 (control $=46 \pm$ $2 \%$; RNAi-selected $=47 \pm 1 \%$ ). Although the difference was small, significantly greater egg hatch was noted in the control relative to the RNAi-selected colony although the difference was during G5 (control $=57 \pm 3 \%$; RNAi-selected $=50 \pm 4 \%$ ). In general, the results of egg viability tests would suggest that the effect of RNAi exposure on egg viability is moderate to insignificant.

Prior to dividing the initial population into RNAi-selected and control colonies (G2), the $\mathrm{LC}_{50}$ was estimated to be $55.4 \mathrm{ng} / \mathrm{cm}^{2}$ (Table 4). At G4, the $\mathrm{LC}_{50}$ for the control was $24.9 \mathrm{ng} / \mathrm{cm}^{2}$ and the RNAi-selected colony was $16.4 \mathrm{ng} / \mathrm{cm}^{2}$ with confidence intervals overlapping for all values (Table 4). During G7, the $\mathrm{LC}_{50}$ generated for neonates from the control colony was $5.12 \mathrm{ng} / \mathrm{cm}^{2}$ (Table 4). At G13, mortality of southern corn rootworm adults from both colonies exposed to the $\mathrm{LC}_{90}\left(210 \mathrm{ng} / \mathrm{cm}^{2}\right.$ calculated at G4) were similar in both the control and selected colonies after $10 \mathrm{~d}$, reaching $97 \%$ $( \pm 1.7)$ in control and $91 \%( \pm 4.1)$ in RNA-selected colony (Fig. 3$)$.

\section{Population Growth Parameters During Larval Selection}

Growth rate in continuous time $\left(r_{m}\right)$ and in discrete time $(\lambda)$ were significantly greater for the control strain when compared to the RNAiselected colony in G9 $(P<0.0001)$ (Table 5). Generation time $(T)$ was significantly greater for the RNAi-selected colony during generations G9 $(P<0.0001)$ and G10 $(P<0.0001)$ when compared to control (Table 5). DT was significantly greater for the control colony on G9 $(P<0.0001)$, but significantly smaller than RNAi-selected colony on G10 $(P<0.0001)$ (Table 5$)$. Net reproductive rate $\left(R_{0}\right)$ was significantly greater for the control colony when compared to the RNAi-selected colony during G9 $(P<0.0001)$, but was not significantly different on G10 $(P=0.3045)$ (Table 5).

\section{Adult Emergence During Larval Selection}

Delays in adult emergence were observed in each generation of larval selection, as illustrated in Fig. 4 and Table 6. During G9, $E_{\max }$ $(t=0.0033)$ and $E_{\text {end }}(t=0.0022)$ were significantly different between control and RNAi-selected colonies, with delays ranging from 5 to $6 \mathrm{~d}$ for the RNAi-selected relative to the control. Although the difference in number of days to reach the parameters $E_{\text {onset }}$ and $E_{\text {duration }}$ at G9 in RNAi-selected and control were $4 \mathrm{~d}$ and $2 \mathrm{~d}$, respectively, differences were not statistically significant. In G10, the parameters $E_{\text {onsect }}, E_{\text {max }}$, and $E_{\text {end }}$ were significantly different between control and RNAi-selected colonies, with the RNAi-selected colony taking from $2 \mathrm{~d}$ to $8 \mathrm{~d}$ longer to reach each parameter when compared to control (Fig. 4; Table 6).

\section{Discussion}

Selection for resistance to synthetic insecticides as well as purified Bt toxins and transgenic plants that express Bt toxins has been performed with many insect pests under laboratory conditions. Although the evolution of resistance under laboratory conditions does not necessarily indicate that resistance will also evolve under field conditions with high selection pressure nor will laboratory resistance affect pesticide efficacy in the field, it may provide insight into potential resistance mechanisms (Keiding 1986, Georghiou 1994, Tabashnik et al. 2014). Additionally, resistant populations are essential for studies of heritability and genetics, as well as providing insight into recommendations for preventive resistance management tactics (Ferré and Van Rie 2002, Meihls et al. 2011).

Results of the present study indicate that susceptibility of southern corn rootworm to vATPase-A dsRNA did not change (Fig. 3) after a total of seven generations of selection with concentrations of dsRNA that should have caused significant mortality in both adults and larvae (Tables 1 and 2). It is not possible to estimate the intensity of selection across the various generations because exposure conditions (dsRNA concentration used) were continually adjusted to allow insects to survive and produce enough individuals to continue the subsequent generations; again, if higher number of eggs were laid by surviving females or higher number of adults emerged from containers after larval selection, dsRNA concentration was increased compared to previous generation (Tables 1 and 2 ). However, such changes in selection may more accurately reflect field conditions if adults or especially larvae move from transgenic to refuge plants and vice versa in a blended refuge environment. In a study of resistance selection to Bt in western corn rootworm, Meihls et al. (2008) did not see change in susceptibility of western corn rootworm to $\mathrm{Bt}$ toxin when neonates were reared on $\mathrm{Bt}$ corn expressing Cry3Bb1 for short periods and then transferred to isoline corn to complete development. However, when reared continuously on Cry3Bb1 expressing plants, resistance evolved in as few as three generations (Meihls et al. 2008). Even though we used artificial diet during selection for resistance and a different species than western corn rootworm in our experiments, we did not report resistance evolution in southern corn rootworm after adults or neonates fed for a limited time on dsRNA before offered untreated diet (adult selection) or transferred to untreated corn plants (larval selection), in similar ways as in Meihls et all (2008).

Our results indicate that southern corn rootworm susceptibility to $v$ ATPase-A dsRNA overlaid on artificial diet did not change

Table 4. Lethal concentrations ( $\mathrm{LC}_{50}, 95 \%$ confidence interval) calculated for control and RNAi-selected colonies during selection for resistance to vATPase-A dsRNA

\begin{tabular}{|c|c|c|c|c|c|}
\hline Life stage & Generation & Colony & ng dsRNA $/ \mathrm{cm}^{2}(95 \% \mathrm{CI})$ & Slope $( \pm \mathrm{SE})$ & $X^{2}(\mathrm{df})$ \\
\hline \multirow[t]{3}{*}{ Adult } & 2 & Control (initial) & $55.4(29.7-103.9)$ & $1.05(0.14)$ & $2.94(3)$ \\
\hline & 4 & Control & $24.9(16.2-38.2)$ & $2.26(0.39)$ & $0.02(3)$ \\
\hline & & RNA & $16.4(2.34-73.9)$ & $1.43(0.23)$ & $9.22(4)$ \\
\hline Larvae & 7 & Control & $5.12(1.84-15.03)$ & $0.58(0.13)$ & $1.16(4)$ \\
\hline
\end{tabular}




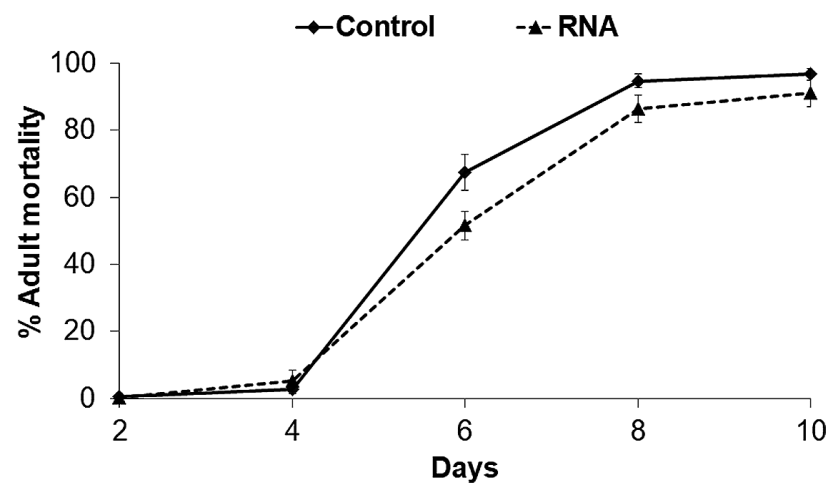

Fig. 3. Southern corn rootworm adult mortality during $10 \mathrm{~d}$ of exposure to VATPase-A dsRNA to $210 \mathrm{ng} / \mathrm{cm}^{2}$ in RNAi-selected and control colonies. Data points are means $( \pm S E)$ of 30 replicates containing 10 adults per replicate calculated for control and RNA exposed mortality values.

Table 5. Comparison of southern corn rootworm population growth parameters (mean $\pm \mathrm{SE}$ ) between control and RNAi-selected populations during two generations (9-10) after neonates were exposed to vATPase-A dsRNA

\begin{tabular}{|c|c|c|c|c|c|c|c|c|c|c|}
\hline \multirow[t]{2}{*}{ Generation } & \multicolumn{2}{|c|}{$r_{m}$} & \multicolumn{2}{|c|}{$R_{0}$} & \multicolumn{2}{|c|}{$T$} & \multicolumn{2}{|c|}{$D T$} & \multicolumn{2}{|c|}{$\lambda$} \\
\hline & Control & RNAi & Control & RNAi & Control & RNAi & Control & RNAi & Control & RNAi \\
\hline 9 & $0.093 \pm 0.003^{a}$ & $0.025 \pm 0.005$ & $84.3 \pm 6.4$ & $7.4 \pm 11.0$ & $53.1 \pm 0.9$ & $86.7 \pm 1.6^{a}$ & $7.5 \pm 1.0$ & $28.2 \pm 1.7^{a}$ & $1.097 \pm 0.003$ & $1.025 \pm 0.005^{a}$ \\
\hline 10 & $0.039 \pm 0.003^{a}$ & $0.056 \pm 0.002$ & $6.8 \pm 7.8$ & $23.4 \pm 4.9$ & $47.8 \pm 1.1$ & $60.9 \pm 0.7^{a}$ & $18.5 \pm 1.1$ & $12.5 \pm 0.8^{a}$ & $1.040 \pm 0.004$ & $1.058 \pm 0.002^{a}$ \\
\hline
\end{tabular}

$r_{m}$, growth rate in continuous time; $R_{0}$, net reproductive rate (females produced per each female per generation); $T$, mean generation time (days); $D T$, time for the population to double in size (days); $\lambda$, growth rate in discrete time.

aSignificantly different within pair-wise comparison using $\mathrm{R}$, at $\alpha=0.05 . D T$ values are medians because based on the formula $(D T=\log (2) / \mathrm{r})$, some of the ' $r$ ' values in the replicates were too small and they would generate higher and inaccurate values for DT. N for control and RNAi-selected in each generation (provided in Table 2).

after multiple generations of exposure to lethal dsRNA between G2 and G10 (Fig. 3). Among possible reasons that we did not see resistance evolution to RNAi in southern corn rootworm, perhaps the most likely relates to a low frequency of resistant alleles in field populations. Although we initiated the colony from approximately 12,000 adults, if the frequency of resistance was exceedingly low (i.e., <0.0001), it is likely that resistance alleles were absent in the population sampled. Another possibility is that resistant alleles were present in the initial sampling but were lost during normal rearing practices, unrelated to selection. It is also important to note that RNAi-deficient insects can be more susceptible to virus infection and, therefore, might just not survive in the nature (Gammon and Mello 2015). However, our results are still informative and suggest that resistance to RNAi technologies in southern corn rootworm is likely to be rare. Differently from our study that exposed the insects to dsRNA overlaid on artificial diet, Khajuria et al. (2018) reported resistance evolution in western corn rootworm to $\operatorname{Snf} 7$ dsRNA expressed in corn plants.

It should also be noted that southern corn rootworm resistance to any insecticide is rare with the only reported instance to the organochlorine insecticide DDT (Bigger 1963, Chio et al. 1978), although direct comparison of resistant and susceptible southern corn rootworm strains was not reported in those studies. Compared to the western corn rootworm, there is a general lack of reported resistance in southern corn rootworm, and it is possible that results observed for this species do not reflect the same resistance potential as for western corn rootworm. It is known that gene flow or migration of populations is one of the factors that can delay resistance evolution in a population (Roush and Daly 1990). Because southern corn rootworm beetles move from host to host and northern areas of Eastern North America are annually recolonized (Krysan 1986), gene flow of susceptible individuals from different areas may reduce selective pressure, and as a consequence, resistance is rarely observed in field populations in this species. Therefore, southern corn rootworm-resistant alleles to any pesticide may be rare in such a way that we would need much higher number of adult beetles from the field to perform resistance studies.

As previously described, laboratory selection experiments have shown that western corn rootworm resistance evolution to transgenic plants expressing Bt can occur in as few as three generations (Meihls et al. 2008, 2012). Other laboratory selection experiments have shown western corn rootworm resistance evolution to Bt toxins in $\leq 11$ generations of exposure, confirming that western corn rootworm has the potential and an unconditional elasticity to evolve resistance under laboratory conditions (Lefko et al. 2008; Meihls et al. 2008, 2011, 2012, 2016; Oswald et al. 2011; Frank et al. 2013). However, the comparison of susceptibility of southern corn rootworm to $\mathrm{Bt}$ is not appropriate, given that southern corn rootworm is not greatly affected by Bt corn, and that none of the commercial Bt corn available labels southern corn rootworm as target pest.

Although repeated exposure to lethal dsRNA in both adult and larval stages of southern corn rootworm did not affect overall susceptibility, comparisons of growth parameters in selected and control populations allowed evaluation of potential fitness costs in those individuals that survived exposure. In our studies, the population growth parameters measured throughout the larval selection during G9 were consistently higher in the unselected population. Neonates which were selected by exposure to dsRNA and then transferred to corn plants showed $75 \%$ reduction in growth rate $\left(r_{m}\right)$ in G9 when compared to the control (Table 5). Similarly, a reduction in the finite rate of increase $(\lambda)$ for the RNAi-selected colony $(75 \%)$ was observed on G9 (Table 5). The net reproductive rate $\left(R_{0}\right)$ was 12 -fold 

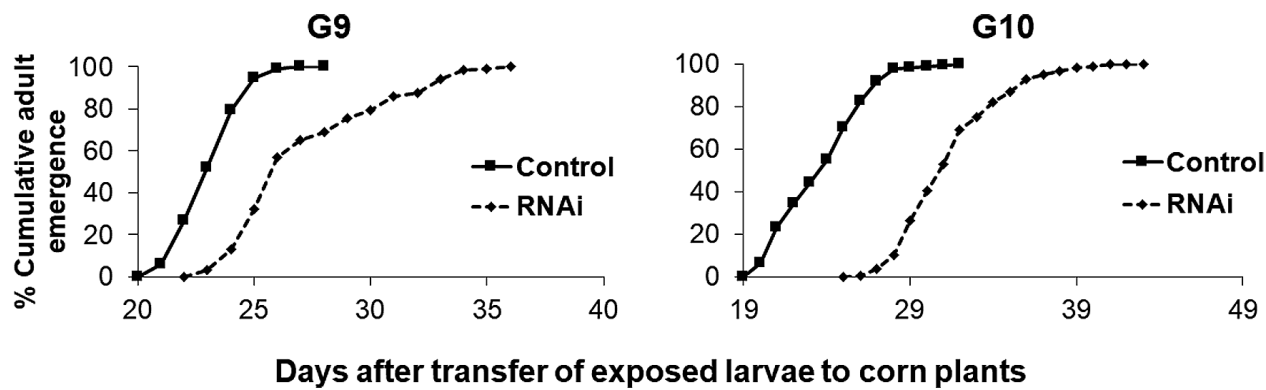

Fig. 4. Percentage of cumulative southern corn rootworm adult emergence in control and RNAi-selected populations from generations 9 and 10 in days after transfer of exposed larvae to corn plants in containers during selection for resistance to vATPase-A dsRNA.

Table 6. Comparison of southern corn rootworm adult emergence parameters (days) (mean \pm SE) between control and RNAi-selected populations during two generations (9-10) after neonates were exposed to vATPase-A dsRNA

\begin{tabular}{|c|c|c|c|c|c|c|c|c|}
\hline \multirow[b]{2}{*}{ Generation } & \multicolumn{2}{|c|}{$E_{\text {onset }}$} & \multicolumn{2}{|c|}{$E_{\max }$} & \multicolumn{2}{|c|}{$E_{\text {duration }}$} & \multicolumn{2}{|c|}{$E_{\text {end }}$} \\
\hline & Control & RNAi & Control & RNAi & Control & RNAi & Control & RNAi \\
\hline 9 & $23 \pm 0.3$ & $27 \pm 2.7$ & $25 \pm 0.3^{a}$ & $30 \pm 1.1$ & $3 \pm 0.2$ & $5 \pm 3.2$ & $26 \pm 0.5^{a}$ & $32 \pm 0.2$ \\
\hline 10 & $21 \pm 1.2^{a}$ & $28 \pm 0.5$ & $23 \pm 1.3^{a}$ & $31 \pm 0.7$ & $6 \pm 0.8$ & $4 \pm 0.6$ & $27 \pm 1.5^{a}$ & $32 \pm 1.0$ \\
\hline
\end{tabular}

$E_{\text {onset }}$, time elapsed before reaching linear emergence; $E_{\text {max }}$, time to reach maximum linear emergence; $E_{\text {duration }}$, duration of linear emergence increase; $E_{\text {end }}$, termination point of the linear emergence.

aSignificantly different within pair-wise comparison using PROC GLIMMIX in SAS, at $\alpha<0.05$. $N$ for control and RNAi-selected in each generation (provided in Table 2).

higher in the control when compared to the RNAi-selected colony during G9, indicating that selection for resistance in larvae can have an impact on reproductive fitness in surviving adults (Table 5). However, net reproductive rate $\left(R_{0}\right)$ was lower on control compared to the RNAi-selected colony in G10 and generation time $(T)$ was lower on control colony in both G9 and G10 (Table 5), which could be an indication of inbreeding. To our knowledge, there has not been any study of inbreeding in the literature for southern corn rootworm. Marrone et al. (1985) reported the comparison of southern corn rootworm reared on a modified artificial diet and corn, and authors concluded that 10 -d development was similar on both rearing media after six generations. This may not be inbreeding but provides evidence of successful selection experiment in southern corn rootworm (Marrone et al. 1985). In the other hand, studies have shown the genetic diversity in inbred western corn rootworm laboratory colonies (Kim et al. 2007) and that this diversity may explain the history of western corn rootworm to evolve resistance to control strategies (Flagel et al. 2014).

We observed a clear detrimental effect of exposure to dsRNA in larvae that survived exposure to dsRNA during larval development. Based on our studies, a delay in developmental time was observed from neonates to adults in the RNAi-selected colony, when compared to the control colony. The effect generated a consistent delay up to $8 \mathrm{~d}$ in adult emergence between generations during larval selection when compared to unselected colony (Table 6; Fig. 4). Delays in western corn rootworm adult emergence up to $8 \mathrm{~d}$ have also been reported to the Bt toxins eCry3.1Ab and mCry3A, and to the combination of both toxins (Hibbard et al. 2011). Storer et al. (2006) documented a range of delays from three to $7 \mathrm{~d}$ in western corn rootworm adult emergence from corn hybrids expressing Cry34/35Ab1 when compared to isoline plants. Hibbard et al. (2010) reported $50 \%$ delay in western corn rootworm adult emergence from corn hybrids expressing mCry3 A protein when compared to non-Bt plants. Murphy et al. (2010) and Clark et al. (2012) reported western corn rootworm males emerging from refuge plants up to $18 \mathrm{~d}$ before females from Cry3Bb1 corn plants, concluding that this delay could affect the random mating between potential heterozygotes emerging from the Bt plants and susceptible individuals emerging from refuge, potentially facilitating resistance evolution. Petzold-Maxwell et al. (2013) reported delay in northern corn rootworm and western corn rootworm adult emergence from Bt plants expressing Cry3Bb1 up to $12 \mathrm{~d}$ when compared to non-Bt plants. Calles-Torrez et al. (2018) reported a delay of $5-7 \mathrm{~d}$ to reach $50 \%$ cumulative adult emergence in western corn rootworm and northern corn rootworm from plants expressing proteins Cry34/35Ab1, Cry3Bb1, or both pyramided. Pereira et al. (2017a) reported sublethal effects of exposure to dsRNAs in southern corn rootworm including delay in larval development, which could consequently lead to a delay in adult emergence. Random mating between susceptible and potential resistant beetles is one of the key assumptions for the transgenic plants to be effective and durable in the field (Andow et al. 2016). Therefore, the delay in adult emergence found in our study could possibly affect the mating synchronism in the field and consequently affect corn rootworm resistance management.

It is important to point out that selection for resistance utilizing artificial diet to expose insects to the toxin may not be the best methodology to compare with field-evolved resistance. However, corn plants expressing dsRNA are not available and when available, they will be pyramided with Bt proteins. Current RNAi technology will be deployed predominantly to target western corn rootworm, but it can also affect southern corn rootworm as shown in previous studies (Pereira et al. 2016, 2017a). Additionally, exposure to toxins often has consequences to fitness (in this case the delay in adult emergence), and could possibly indicate initial levels of resistance evolution (Pereira et al. 2017a). Therefore, resistance studies are valuable, even with close relatives to help understanding potential resistance mechanisms, preventing resistance evolution, and improving resistance management. Despite that the dsRNA used in our study 
(vATPase-A) is different from the dsRNA that will be deployed in corn plants soon $(S n f 7)$, the importance of developing a resistant colony to RNAi in the lab is essential for cross-resistance studies. Khajuria et al. (2018) reported that western corn rootworm resistant to $\operatorname{Snf7}$ exhibited cross-resistance to other dsRNAs tested. The information of cross-resistance with other dsRNAs is not new, given that Tabara et al. (1999) reported the insensitivity of a mutant-laboratory generated nematode strain of C. elegans resistant to several dsRNAs. Therefore, testing if an RNAi-resistant strain of corn rootworm is cross-resistant with other dsRNAs is essential regardless of the species and the target gene.

In conclusion, we documented the lack of resistance evolution in southern corn rootworm after seven generations of selection in both adults ( 4 generations) and larvae ( 3 generations) to $v$ ATPase- $A$ dsRNA on artificial diet. Studies of selection for resistance and sublethal effects of RNAi involving other corn rootworm species, especially western corn rootworm, should continue. Such experiments will become more feasible after corn plants expressing dsRNA become commercially available (EPA 2017, Head et al. 2017, Moar et al. 2017). Our study also documented that exposures of southern corn rootworm to dsRNA affected important life history traits and fitness, especially causing a delay in adult emergence after neonate exposure. These results suggest that exposure to dsRNA in transgenic plants could affect both larvae and adults. The initial release of corn plants expressing RNAi traits is projected to start in the near future. Therefore, resistance risk assessment for any targeted Diabrotica species will be key to delay resistance evolution.

\section{Acknowledgments}

We are grateful for the laboratory assistance from Hugo Monteiro, Thais Teixeira, and Catarina Lopes for help with bioassays and colony rearing. We thank the valuable comments from Dr. Bruce E. Hibbard and anonymous reviewers to improve the manuscript. A special thanks to Terrence Spencer for the help in collecting and rearing southern corn rootworm. This research did not receive any specific grant from funding agencies in the public, commercial, or not-for-profit sectors. A.E.P., B.T., L.J.M., and B.D.S. conceived research. A.E.P. conducted experiments. A.E.P. and B.T. analyzed data and conducted statistical analysis. A.E.P., B.D.S., L.J.M. wrote the manuscript. B.D.S. secured funding. All authors read and approved the manuscript.

\section{References Cited}

Abbott, W. 1925. A method of computing the effectiveness of an insecticide. J. Econ. Entomol. 18: 265-267.

Ahmad, A., I. Negri, W. Oliveira, C. Brown, P. Asiimwe, B. Sammons, M. Horak, C. Jiang, and D. Carson. 2016. Transportable data from non-target arthropod field studies for the environmental risk assessment of genetically modified maize expressing an insecticidal double-stranded RNA. Transgenic Res. 25: 1-17.

Andow, D. A., S. G. Pueppke, A. W. Schaafsma, A. J. Gassmann, T. W. Sappington, L. J. Meinke, P. D. Mitchell, T. M. Hurley, R. L. Hellmich, and R. P. Porter. 2016. Early detection and mitigation of resistance to Bt maize by western corn rootworm (Coleoptera: Chrysomelidae). J. Econ. Entomol. 109: 1-12.

Arant, F. S. 1929. Biology and control of the southern corn rootworm, vol. 230. Agricultural Experiment Station of the Alabama Polytechnic Institute. Auburn University, Auburn, AL. p. 48.

Bachman, P. M., R. Bolognesi, W. J. Moar, G. M. Mueller, M. S. Paradise, P. Ramaseshadri, J. Tan, J. P. Uffman, J. Warren, B. E. Wiggins, et al. 2013. Characterization of the spectrum of insecticidal activity of a doublestranded RNA with targeted activity against Western Corn Rootworm (Diabrotica virgifera virgifera LeConte). Transgenic Res. 22: 1207-1222.

Bachman, P. M., K. M. Huizinga, P. D. Jensen, G. Mueller, J. Tan, J. P. Uffman, and S. L. Levine. 2016. Ecological risk assessment for DvSnf7 RNA: a plant-incorporated protectant with targeted activity against western corn rootworm. Regul. Toxicol. Pharmacol. 81: 77-88.

Ball, H. J., and Weekman, G. T. 1962. Insecticide resistance in the adult western corn rootworm in Nebraska. J. Econ. Entomol. 55: 439-441.

Baum, J. A., T. Bogaert, W. Clinton, G. R. Heck, P. Feldmann, O. Ilagan, S. Johnson, G. Plaetinck, T. Munyikwa, M. Pleau, et al. 2007. Control of coleopteran insect pests through RNA interference. Nat. Biotechnol. 25: 1322-1326.

Bigger, J. 1963. Corn rootworm resistance to chlorinated hydrocarbon insecticides in Illinois. J. Econ. Entomol. 56: 118-119.

Boetel, M. A., B. W. Fuller, and P. D. Evenson. 2003. Emergence of adult northern and western corn rootworms (Coleoptera: Chrysomelidae) following reduced soil insecticide applications. J. Econ. Entomol. 96: 714-729.

Bolognesi, R., P. Ramaseshadri, J. Anderson, P. Bachman, W. Clinton, R. Flannagan, O. Ilagan, C. Lawrence, S. Levine, W. Moar, et al. 2012. Characterizing the mechanism of action of double-stranded RNA activity against western corn rootworm (Diabrotica virgifera virgifera LeConte). PLoS One 7: e47534.

Branson, T., and J. Jackson. 1988. An improved diet for adult Diabrotica virgifera virgifera (Coleoptera: Chrysomelidae). J. Kans. Entomol. Soc. 61: 353-355.

Calles-Torrez, V., J. J. Knodel, M. A. Boetel, C. D. Doetkott, K. K. Podliska, J. K. Ransom, P. Beauzay, B. W. French, and B. W. Fuller. 2018. Transgenic Bt corn, soil insecticide, and insecticidal seed treatment effects on corn rootworm (Coleoptera: Chrysomelidae) beetle emergence, larval feeding injury, and corn yield in North Dakota. J. Econ. Entomol. 111: 348-360.

Chio, H., C.-S. Chang, R. L. Metcalf, and J. Shaw. 1978. Susceptibility of four species of Diabrotica to insecticides. J. Econ. Entomol. 71: 389-393.

Clark, T., D. Frank, B. French, L. Meinke, D. Moellenbeck, T. Vaughn, and B. Hibbard. 2012. Mortality impact of MON863 transgenic maize roots on western corn rootworm larvae in the field. J. App. Entomol. 136: 721-729.

Dybing, C. D., P. Evenson, and C. Lay. 1988. Relationships among daily flower production, length of the flowering period, and seed yield of flax. Crop Sci. 28: 287-292.

Environmental Protection Agency (EPA). 2017. Pesticide registration: EPA registers innovative tool to control corn rootworm. https://www.epa.gov/ pesticide-registration/epa-registers-innovative-tool-control-corn-rootworm.

Ferré, J., and J. Van Rie. 2002. Biochemistry and genetics of insect resistance to Bacillus thuringiensis. Ann. Rev. Entomol. 47: 501-533.

Fire, A. Z. 2007. Gene silencing by double-stranded RNA (Nobel Lecture). Angew. Chem. Int. Ed. 46: 6966-6984.

Fire, A., S. Xu, M. K. Montgomery, S. A. Kostas, S. E. Driver, and C. C. Mello. 1998. Potent and specific genetic interference by double-stranded RNA in Caenorhabditis elegans. Nature. 391: 806-811.

Fishilevich, E., A. M. Vélez, C. Khajuria, M. L. Frey, R. L. Hamm, H. Wang, G. A. Schulenberg, A. J. Bowling, H. E. Pence, P. Gandra, et al. 2016. Use of chromatin remodeling ATPases as RNAi targets for parental control of western corn rootworm (Diabrotica virgifera virgifera) and Neotropical brown stink bug (Euschistus heros). Insect Biochem. Mol. Biol. 71: 58-71.

Flagel, L. E., R. Bansal, R. A. Kerstetter, M. Chen, M. Carroll, R. Flannagan, T. Clark, B. S. Goldman, and A. P. Michel. 2014. Western corn rootworm (Diabrotica virgifera virgifera) transcriptome assembly and genomic analysis of population structure. BMC Genomics 15: 195.

Frank, D. L., A. Zukoff, J. Barry, M. L. Higdon, and B. E. Hibbard. 2013. Development of resistance to eCry3.1Ab-expressing transgenic maize in a laboratory-selected population of western corn rootworm (Coleoptera: Chrysomelidae). J. Econ. Entomol. 106: 2506-2513.

Gammon, D. B., and C. C. Mello. 2015. RNA interference-mediated antiviral defense in insects. Curr. Opin. Insect Sci. 8: 111-120.

Gassmann, A. J., J. L. Petzold-Maxwell, R. S. Keweshan, and M. W. Dunbar. 2011. Field-evolved resistance to Bt maize by western corn rootworm. PLoS One 6: e22629.

Gassmann, A. J., R. B. Shrestha, S. R. Jakka, M. W. Dunbar, E. H. Clifton, A. R. Paolino, D. A. Ingber, B. W. French, K. E. Masloski, J. W. Dounda, et al. 2016. Evidence of resistance to Cry34/35Ab1 corn by western corn rootworm (Coleoptera: Chrysomelidae): root injury in the field and larval survival in plant-based bioassays. J. Econ. Entomol. 109: 1872-1880. 
Georghiou, G. P. 1994. Principles of insecticide resistance management. Phytoprotection. 75: 51-59.

Gotelli, N. J. 1995. A primer of ecology. Sinauer Associates Incorporated, Sunderland, MA.

Gu, L., and D. C. Knipple. 2013. Recent advances in RNA interference research in insects: implications for future insect pest management strategies. Crop Prot. 45: 36-40.

Head, G. P., M. W. Carroll, S. P. Evans, D. M. Rule, A. R. Willse, T. L. Clark, N. P. Storer, R. D. Flannagan, L. W. Samuel, and L. J. Meinke. 2017. Evaluation of SmartStax and SmartStax PRO maize against western corn rootworm and northern corn rootworm: efficacy and resistance management. Pest Manag. Sci. 73: 1883-1899.

Hibbard, B. E., T. L. Clark, M. R. Ellersieck, L. N. Meihls, A. A. El Khishen, V. Kaster, H. Y. Steiner, and R. Kurtz. 2010. Mortality of western corn rootworm larvae on MIR604 transgenic maize roots: field survivorship has no significant impact on survivorship of F1 progeny on MIR604. J. Econ. Entomol. 103: 2187-2196.

Hibbard, B. E., D. L. Frank, R. Kurtz, E. Boudreau, M. R. Ellersieck, and J. F. Odhiambo. 2011. Mortality impact of Bt transgenic maize roots expressing eCry3.1Ab, mCry3 A, and eCry3.1Ab plus mCry3A on western corn rootworm larvae in the field. J. Econ. Entomol. 104: 1584-1591.

Huvenne, H., and G. Smagghe. 2010. Mechanisms of dsRNA uptake in insects and potential of RNAi for pest control: a review. J. Insect Physiol. 56: 227-235.

Isely, D. 1929. The southern corn rootworm, vol. 232. Arkansas Agricultural Experiment Station. University of Arkansas, Fayetteville, AR. p.31.

Jackson, J. J. 1986. Rearing and handling of Diabrotica virgifera and Diabrotica undecimpunctata howardi, pp. 25-47. In J. L. M. Krysan, Thomas A (eds.), Methods for the study of pest Diabrotica. Springer, New York, NY.

Keiding, J. 1986. Prediction or resistance risk assessment, pp. 279-297. Pesticide resistance: Strategies and tactics for management. Committee on strategies for the management of pesticide resistant pest populations. National Academy Press, Washington, DC.

Khajuria, C., A. M. Vélez, M. Rangasamy, H. Wang, E. Fishilevich, M. L. Frey, N. P. Carneiro, P. Gandra, K. E. Narva, and B. D. Siegfried. 2015. Parental RNA interference of genes involved in embryonic development of the western corn rootworm, Diabrotica virgifera virgifera LeConte. Insect Biochem. Mol. Biol. 63: 54-62.

Khajuria, C., S. Ivashuta, E. Wiggins, L. Flagel, W. Moar, M. Pleau, K. Miller, Y. Zhang, P. Ramaseshadri, C. Jiang, et al. 2018. Development and characterization of the first dsRNA-resistant insect population from western corn rootworm, Diabrotica virgifera virgifera LeConte. PLoS One 13: e0197059.

Kim, K. S., B. W. French, D. V. Sumerford, and T. W. Sappington. 2007. Genetic diversity in laboratory colonies of western corn rootworm (Coleoptera: Chrysomelidae), including a nondiapause colony. Environ. Entomol. 36: 637-645.

Koči, J., P. Ramaseshadri, R. Bolognesi, G. Segers, R. Flannagan, and Y. Park. 2014. Ultrastructural changes caused by Snf7 RNAi in larval enterocytes of western corn rootworm (Diabrotica virgifera virgifera Le Conte). PLoS One 9: e83985.

Krysan, J. L. 1986. Introduction: biology, distribution, and identification of pest Diabrotica, pp. 1-23. In J. L. M. Krysan, Thomas A (eds.), Methods for the study of pest Diabrotica. Springer, New York, NY.

Lefko, S., T. Nowatzki, S. Thompson, R. Binning, M. Pascual, M. Peters, E. Simbro, and B. Stanley. 2008. Characterizing laboratory colonies of western corn rootworm (Coleoptera: Chrysomelidae) selected for survival on maize containing event DAS-59122-7. J. App. Entomology. 132: 189-204.

LeOra. 1987. POLO-PC: a user's guide to probit or logit analysis. LeOra Software Berkeley, CA.

Levine, E., J. L. Spencer, S. A. Isard, D. W. Onstad, and M. E. Gray. 2002. Adaptation of the western corn rootworm to crop rotation: evolution of a new strain in response to a management practice. Am. Entomol. 48: 94-107.

Levine, S. L., J. Tan, G. M. Mueller, P. M. Bachman, P. D. Jensen, and J. P. Uffman. 2015. Independent action between DvSnf7 RNA and Cry3Bb1 protein in southern corn rootworm, Diabrotica undecimpunctata howardi and Colorado potato beetle, Leptinotarsa decemlineata. PLoS One 10: e0118622.

Ludwick, D., L. Meihls, K. Ostlie, B. Potter, L. French, and B. Hibbard. 2017. Minnesota field population of western corn rootworm (Coleoptera: Chrysomelidae) shows incomplete resistance to Cry34Ab1/Cry35Ab1 and Cry3Bb1. J. Appl. Entomol. 142: 28-40.

Marrone, P. G., F. D. Ferri, T. R. Mosley, and L. J. Meinke. 1985. Improvements in laboratory rearing of the southern corn rootworm, Diabrotica undecimpuncta howardi Barber (Coleoptera: Chrysomelidae), on an artificial diet and corn. J. Econ. Entomol. 78: 290-293.

Meihls, L. N., M. L. Higdon, B. D. Siegfried, N. J. Miller, T. W. Sappington, M. R. Ellersieck, T. A. Spencer, and B. E. Hibbard. 2008. Increased survival of western corn rootworm on transgenic corn within three generations of on-plant greenhouse selection. Proc. Natl. Acad. Sci. U. S. A. 105: 19177-19182.

Meihls, L. N., M. L. Higdon, M. Ellersieck, and B. E. Hibbard. 2011. Selection for resistance to mCry3A-expressing transgenic corn in western corn rootworm. J. Econ. Entomol. 104: 1045-1054.

Meihls, L. N., M. L. Higdon, M. R. Ellersieck, B. E. Tabashnik, and B. E. Hibbard. 2012. Greenhouse-selected resistance to Cry3Bb1-producing corn in three western corn rootworm populations. PLoS One 7: e51055.

Meihls, L. N., D. L. Frank, M. R. Ellersieck, and B. E. Hibbard. 2016. Development and characterization of MIR604 resistance in a Western Corn rootworm population (Coleoptera: Chrysomelidae). Environ. Entomol. 45: 526-536.

Meinke, L. J., F. Gould, and J. Van Duyn. 1985. Soybean: a larval host for the southern corn rootworm (Coleoptera: Chrysomelidae). Fla. Entomol. 68: 496-498.

Meinke, L. J., B. D. Siegfried, R. J. Wright, and L. D. Chandler. 1998. Adult susceptibility of Nebraska western corn rootworm (Coleoptera: Chrysomelidae) populations to selected insecticides. J. Econ. Entomol. 91: 594-600.

Miller, N. J., T. Guillemaud, R. Giordano, B. D. Siegfried, M. E. Gray, L. J. Meinke, and T. W. Sappington. 2009. Genes, gene flow and adaptation of Diabrotica virgifera virgifera. Agric. For. Entomol. 11: 47-60.

Moar, W., C. Khajuria, M. Pleau, O. Ilagan, M. Chen, C. Jiang, P. Price, B. McNulty, T. Clark, and G. Head. 2017. Cry3Bb1-resistant western corn rootworm, diabrotica virgifera virgifera (LeConte) does not exhibit crossresistance to DvSnf7 dsRNA. PLoS One 12: e0169175.

Murphy, A. F., M. D. Ginzel, and C. H. Krupke. 2010. Evaluating western corn rootworm (Coleoptera: Chrysomelidae) emergence and root damage in a seed mix refuge. J. Econ. Entomol. 103: 147-157.

Oswald, K. J., B. W. French, C. Nielson, and M. Bagley. 2011. Selection for Cry3Bb1 resistance in a genetically diverse population of nondiapausing western corn rootworm (Coleoptera: Chrysomelidae). J. Econ. Entomol. 104: 1038-1044.

Pereira, A. E., H. Wang, S. N. Zukoff, L. J. Meinke, B. W. French, and B. D. Siegfried. 2015. Evidence of field-evolved resistance to bifenthrin in western corn rootworm (Diabrotica virgifera virgifera LeConte) populations in western nebraska and kansas. PLoS One 10: e0142299.

Pereira, A. E., N. P. Carneiro, and B. D. Siegfried. 2016. Comparative susceptibility of southern and western corn rootworm adults and larvae to $v$ ATPase$A$ and Snf7 dsRNAs. J. RNAi Gene Silencing. 12: 528-535.

Pereira, A. E., A. M. Vélez, L. J. Meinke, and B. D. Siegfried. 2017a. Sublethal effects of $v$ ATPase- $A$ and Snf7 dsRNAs on biology of southern corn rootworm, diabrotica undecimpunctata howardi Barber. J. Econ. Entomol. 110: 2545-2553.

Pereira, A. E., D. Souza, S. N. Zukoff, L. J. Meinke, and B. D. Siegfried. 2017b. Cross-resistance and synergism bioassays suggest multiple mechanisms of pyrethroid resistance in western corn rootworm populations. PLoS One 12: e0179311.

Petzold-Maxwell, J. L., X. C.-Stewart, B. W. French, and A. J. Gassmann. 2013. Adaptation by western corn rootworm (Coleoptera: Chrysomelidae) to Bt maize: inheritance, fitness costs, and feeding preference. J. Econ. Entomol. 105: 1407-1418.

Pleau, M., J. E. Huesing, G. P. Head, and D. J. Feir. 2002. Development of an artificial diet for the western corn rootworm. Entomol. Exp. Appl. 105: $1-11$. 
Pollard, D. A., and M. V. Rockman. 2013. Resistance to germline RNA interference in a Caenorhabditis elegans wild isolate exhibits complexity and nonadditivity. G3: Genesl Genomesl Genetics. 3: 941-947.

Rangasamy, M., and B. D. Siegfried. 2012. Validation of RNA interference in western corn rootworm Diabrotica virgifera virgifera LeConte (Coleoptera: Chrysomelidae) adults. Pest Manag. Sci. 68: 587-591.

R Core Team. 2017. R: A language and environment for statistical computing. R Foundation for Statistical Computing, Vienna, Austria.

Riedell, W. E. 1990. Rootworm and mechanical damage effects on root morphology and water relations in maize. Crop Sci. 30: 628-631.

Roush, R. T., and J. C. Daly. 1990. The role of population genetics in resistance research and management, pp. 97-152. In R. T. Roush and B. E. Tabashnik (eds.), Pesticide resistance in arthropods. Chapman and Hall, New York, NY.

Stilwell, A. R., R. J. Wright, T. E. Hunt, and E. E. Blankenship. 2010. Degreeday requirements for alfalfa weevil (Coleoptera: Curculionidae) development in eastern Nebraska. Environ. Entomol. 39: 202-209.

Storer, N. P., J. M. Babcock, and J. M. Edwards. 2006. Field measures of western corn rootworm (Coleoptera: Chrysomelidae) mortality caused by Cry34/35Ab1 proteins expressed in maize event 59122 and implications for trait durability. J. Econ. Entomol. 99: 1381-1387.

Tabara, H., M. Sarkissian, W. G. Kelly, J. Fleenor, A. Grishok, L. Timmons, A. Fire, and C. C. Mello. 1999. The rde-1 gene, RNA interference, and transposon silencing in C. elegans. Cell. 99: 123-132.
Tabashnik, B. E., D. Mota-Sanchez, M. E. Whalon, R. M. Hollingworth, and Y. Carrière. 2014. Defining terms for proactive management of resistance to Bt crops and pesticides. J. Econ. Entomol. 107: 496-507.

Tinsley, N., R. Estes, and M. Gray. 2013. Validation of a nested error component model to estimate damage caused by corn rootworm larvae. J. App. Entomol. 137: 161-169.

Vélez, A. M., C. Khajuria, H. Wang, K. E. Narva, and B. D. Siegfried. 2016 Knockdown of RNA interference pathway genes in western corn rootworms (Diabrotica virgifera virgifera Le Conte) demonstrates a possible mechanism of resistance to lethal dsRNA. PLoS One 11: e0157520.

Wang, H., B. S. Coates, H. Chen, T. W. Sappington, T. Guillemaud, and B. D. Siegfried. 2013. Role of a $\gamma$-aminobutryic acid (GABA) receptor mutation in the evolution and spread of Diabrotica virgifera virgifera resistance to cyclodiene insecticides. Insect Mol. Biol. 22: 473-484.

Wangila, D. S., A. J. Gassmann, J. L. Petzold-Maxwell, B. W. French, and L. J. Meinke. 2015. Susceptibility of nebraska western corn rootworm (Coleoptera: Chrysomelidae) populations to Bt corn events. J. Econ. Entomol. 108: 742-751.

Zhu, K. Y., G. E. Wilde, R. A. Higgins, P. E. Sloderbeck, L. L. Buschman, R. A. Shufran, R. J. Whitworth, S. R. Starkey, and F. He. 2001. Evidence of evolving carbaryl resistance in western corn rootworm (Coleoptera: Chrysomelidae) in areawide-managed cornfields in north central Kansas. J. Econ. Entomol. 94: 929-934. 